\title{
THE COMPARATIVE ANALYSIS ON PRIORITIES OF LEARNING FACTORS BETWEEN CHINA AND KOREA
}

\begin{abstract}
This study aims to identify the success factors of e(electronic)-learning using information \& communication technology (ICT). For this purpose, this study focuses on identifying differences in success factors among countries in terms of differences in ICT levels and utilization among countries. As a way of solving this problem, this study is based on Analytic Hierarchy Process (AHP). At this point, Analytic Network Process (ANP) is also used to check the independence among elements. We use the compatibility index provided by AHP to compare the results of the two countries (China and Korea) and identify differences. This study summarizes the results of the study and presents future research.
\end{abstract}

Keywords: e-learning, success factors, priorities, AHP, ANP, compatibility index

\section{Introduction}

The development of information \& communication technology (ICT) has become the basis for a new paradigm called the $4^{\text {th }}$ Industrial Revolution. In this digital environment, E(electronic)-learning is attracting attention as a learning method that transcends time and space.

E-learning is the online delivery of information for purposes of education, training, or knowledge management (Turban et. al, 2011). E-learning can refer to any method of computer/network-enhanced learning (www.wikipedia.org). E-learning project management is usually composed of 6 items such as planning, content gathering and analysis, instructional design, story boarding, development and production and quality assurance, which is connected to technological advances such as simulations, virtual worlds, and open source software, wireless networking have reshaped the e-leaning landscape.

Korea is at the forefront in adopting new technologies for learning by encouraging the development of Internet learning using digital devices. This is an active effort to develop Korea into a ubiquitous learning society. In the case of China, ICT development is demanding education according to information. In time, e-Learning international 
suppliers began introducing e-learning products to China (Qian, 2009). Nevertheless, most e-learning applications do not meet the needs of learners and consequently elearning programs are not meeting the needs of the organization for success.

The purpose of this study is to determine whether there is a difference in the priority of elearning requirements according to the degree of the e-learning diffusion and of perception, and the level of related technology. Therefore, this study aims to compare the priorities of requirements for e-learning users in Korea and China.

\section{Literature Review}

There are many kinds of definition related to e-learning and those have been used as replacement of e-learning such as online learning, distance learning, and web-based learning or computer-based learning. Concerning success factors of e-learning, Hassanzadeh et al. (2012) suggested that information and content quality is often seen as a key antecedent for user satisfaction. Chang (2013) showed that web quality significantly and positively influences user value and user satisfaction. Alsabawy et al. (2013) propose technical system quality has a significant positive effect on satisfaction in e-learning context. E-learning lets individuals fulfill their educational needs via a connected e-learning organization. We define e-learning as instruction delivered on a digital device (such as computer, tablet, or smart phone) that is intended to support learning.

Concerning benefits of e-learning, it can enable individuals to take charge of their own lifelong learning by eliminating barriers of time, distance, and socioeconomic status. Elearning of new content will help organizations and countries adapt to the demands of the internet economy by training their workers and educating their citizens. E-learning can save money, reduce travel time, increase access to experts, enable large numbers of students to take classes simultaneously, provide on-demand education, and enable selfpaced learning. It also may make learning less frustrating by making it more interactive and engaging.

\section{Research Design/Methodology}

Those benefits are usually to satisfy requirements in terms of e-learning. Just as elearning has been dealt with many different approaches such as behavioral, cognitive, social and psychological theories [Gillani 2003], we can classify those requirements into different number of categories by different approach or perspective of e-learning. In this study, we classify the requirements by adopting the viewpoint of contents users.

First of all, in the recent ICT environment, e-learning is divided into two categories: digital content and its provision on the web. The second level of digital content is 
composed of usability, understandability, and attention. The 3rd level is composed of 9 sub-factors, 3 factors for each upper level factor. Lower level of web operations is composed of web-based software solutions [ISO/IEC 25000] and additional support services. The $3 \mathrm{rd}$ level is totally composed of 9 sub-factors as $<$ Table $1>$.

Primarily AHP [Saaty 1980], which has been knows as an appropriate method that translates subjective judgment into objective priorities, is used to identify the priorities of requirements in the given hierarchy. ANP [Saaty 1996] is used to test the independence of factors at level 2.

The survey was conducted assuming the differences between Korea and China. This implies that not only ICT environment, diffusion level, and user level (familiarity level), but also the culture of education and the underlying culture and ideology will be reflected in the results. To verify this, we use a compatibility index provided by AHP.

$<$ Table 1: Requirements $>$

\begin{tabular}{|c|c|c|c|}
\hline Goal & level 1 & level 2 & level 3 \\
\hline \multirow[t]{5}{*}{ E-Learning } & \multirow[t]{3}{*}{ Digital Contents } & Usefulness & $\begin{array}{l}\text { Suitability } \\
\text { Professional authority } \\
\text { Recency }\end{array}$ \\
\hline & & Understandability & $\begin{array}{l}\text { Difficulty appropriateness } \\
\text { Quantity appropriateness } \\
\text { Representation }\end{array}$ \\
\hline & & Interestedness & $\begin{array}{l}\text { Constructive Interest } \\
\text { Intellectual interest } \\
\text { Social interest }\end{array}$ \\
\hline & \multirow[t]{2}{*}{ Web-Operation } & Software solution & $\begin{array}{l}\text { Functionality } \\
\text { Efficiency } \\
\text { Reliability } \\
\text { Convenience } \\
\text { Security }\end{array}$ \\
\hline & & On-Line Support & $\begin{array}{l}\text { Service reliability } \\
\text { Service responsiveness } \\
\text { Emotional empathy } \\
\text { Community usefulness }\end{array}$ \\
\hline
\end{tabular}

\section{Data Analysis}

We surveyed users who ever experienced e-learning contents on web site about the priorities of requirements. Using the consistency ratio of AHP, only consistent data are analyzed. When we aggregate the multiple users' judgements, we used geometric mean 
for the pairwise comparisons because it can keep the reciprocal property in the pairwise comparison matrix. Using the ANP, we tested dependency among factors in level 2.

The main differences between the two countries' significance results are as follows. Chinese users show that the importance of digital content $(0.80)$ is obviously higher than the importance of website operation and support (0.20). On the other hand, the difference between the two categories by the Korean users (0.62: 0.38) is not as large as the difference by Chinese users. This is due to the experience of Korean users who are familiar with e-learning first.

Among the factors of the second level, in the case of China, it is clear that the usability is very important among the factors of digital contents, and understandability and interestedness are important in order $(=0.40: 0.28: 0.12)$. On the other hand, in Korea, the order is the same as that of China, but there is no significant difference in the importance of the three factors (=0.23: 0.20: 0.19). By Korean users, in the sub-factors of web operation, the importance of on-line support items $(0.23)$ is higher than the importance of software solution (0.15). For Chinese users, there is little difference between the two.

The important outcomes of sub-factors in the level 3 are: for Chinese users, the accuracy of the right direction of the content is most important, and the relevance of the content and the freshness of the content are more important than others. In Korea, the level of content suitability and accuracy was recognized as an important item and almost equally than they, community usability and online service stability are importantly recognized.

In this study, the compatibility index was used to test the difference of evaluation between Chinese and Korean users. The differences by the index results of each level were all clear. Thus, it can be concluded that there is a clear difference in perceptions of the components of e-learning among Korean users and Chinese users.

\section{Limitations}

Respondents in this survey are in their 20s by age group and most of them are college students. Thus, the results of this study are considered to be limited to college education or the process of its preparation, and it is difficult to generalize the result for other purposes.

\section{Conclusions}

This study has identified some important factors for developing e - learning using AHP for users in China where digital contents are now developing and users in Korea where digital contents are popularized. 
ISAHP Article: A Style Guide for Paper Proposals To Be Submitted to the International Symposium on the Analytic Hierarchy Process 2018, Hong Kong, HK.

In China, the importance of digital content is much greater than the web operation of it, whereas in Korea the difference of the two factors is not as much as that of China. More specifically, in the case of China for digital content, usability is very important, and understandability and interestedness are important in order. In Korea, in addition to usability, on-line support under web operation is the most important and the other factors are not very different among themselves, which is unlike to the case of China.

In practice, eLearning providers need to pay more attention to the results to meet their needs.

\section{Key References}

ISO/IEC 25000 (2005), Software and System engineering: Software product Quality Requirements and Evaluation (SQuaRE-Guide to SQuaRE).

Turban, E. King, D \& Lang, J. (2011), Introduction to Electronic Commerce 3rd Edi., Borough NJ, Pearson Prentice Hall.

Selim, H.M. (2007), Critical success factors for e-learning acceptance: Confirmatory factor models, Computers and Education 49/2, 396-413.

Saaty T. L. (1980), The Analytic Hierarchy Process, NewYork, McGraw-Hill.

Saaty T. L. (1996), The Analytic Network Process, Pittsburgh, PA: RWS Publications. 